\title{
Predictors of Japanese Workers' Satisfaction with their Annual Health Checkups
}

\author{
Yasushi KUDO' ${ }^{*}$, Yuichi MIWA ${ }^{1,2}$, Jun MIKAMI², Toshihiko OHATA ${ }^{2}$, Toshihiko SATOH ${ }^{3}$, \\ Shigeri KIDO ${ }^{4}$, Yumiko SUGIURA ${ }^{1}$, Masashi TSUNODA ${ }^{1}$ and Yoshiharu AIZAWA ${ }^{1}$ \\ ${ }^{1}$ Department of Preventive Medicine and Public Health, Kitasato University School of Medicine, 1-15-1 \\ Kitasato, Sagamihara, Kanagawa 228-8555, Japan \\ ${ }^{2}$ Tokyo Health Service Association, Tokyo, Japan \\ ${ }^{3}$ Kitasato Clinical Research Center, Kitasato University School of Medicine, Kanagawa, Japan \\ ${ }^{4}$ Department of Fundamentals of Nursing, Kitasato University School of Nursing, Kanagawa, Japan
}

Received April 7, 2008 and accepted December 12, 2008

\begin{abstract}
To seek the factors associated with the degree of Japanese workers' satisfaction with their annual health checkups, a survey with an anonymous self-administered questionnaire was conducted. A total of 1,389 questionnaires were analyzed. The average age of the analyzed subjects was 37.4 yr (range, 18-66 yr). Multiple linear regression analysis showed that the degree of such satisfaction was significantly associated with the effectiveness of annual health checkups, the hassle of receiving them, the receptionist's good manners, cleanliness of the examination site, the long waiting time, privacy invasion issues, anxiety concerning the skills of the persons conducting the examinations, and helpful advice from a physician. Various activities including promoting primary preventions, e.g., medical education must be conducted to convey the effectiveness of annual health checkups to examinees and to reduce the hassle of receiving those checkups. Health checkup staffs must keep their health checkup sites clean and try to find ways to reduce the waiting time. Moreover, they must pay particular attention to examinees' privacy. It is imperative that examinees are not anxious concerning the skills of the persons conducting the examinations. Many examinees want helpful advice from a physician regarding their health management.
\end{abstract}

Key words: Satisfaction, Annual health checkups, Examinee, Workplace, Questionnaire

\section{Introduction}

The degree of patient satisfaction is one of the important indices for evaluating the quality of healthcare ${ }^{1)}$. And there are many reports on patient satisfaction both inside and outside Japan ${ }^{1-6)}$. This idea can also be applied to workers' satisfaction with their annual health checkups. To improve the quality of workers' annual health checkups, it is imperative to investigate their degree of satisfaction with those checkups.

The Industrial Safety and Health Law of Japan stipulates that all workers must undergo annual health checkups $^{7)}$. In accordance with Japanese law, a physician asks examinees about their health conditions during consulta-

*To whom correspondence should be addressed. tions, e.g., subjective symptoms and medical histories ${ }^{7)}$. These consultations will also become opportunities for health education ${ }^{7}$. All workers have to undergo an annual health examination including: height, weight, visual acuity, audiometry, sphygmomanometry, chest x-ray, urinalysis, anemia, liver function, blood lipid and blood sugar tests, and electrocardiography ${ }^{7}$. However, the law also stipulates that, at a physicians' discretion, for workers younger than $40 \mathrm{yr}$ old, with the exception of those who are $35 \mathrm{yr}$ old, the tests for anemia, liver function, blood lipid and blood sugar, and the electrocardiography can be waived $^{7}$.

The results of these checkups serve as references for actions to be taken by occupational health staff after the health checkups to protect workers' health ${ }^{7)}$. Workers are notified of their health checkup results ${ }^{7}$. Workers should 
then use the results of their health checkups to properly manage their own health. However, many of them do not accurately remember the results of their checkups ${ }^{8,9)}$.

It is possible that the improvement in patient satisfaction enhances adherence ${ }^{1)}$. Considering this, it could also be possible that the study of workers' satisfaction with their annual health checkups could become a means for encouraging workers to use the results of those checkups to maintain and promote their own health. This study should be conducted in view of not only improving the quality of the annual health checkups but also so that it will encourage workers to use the results of their checkups for their health. There have been some reports on workers' satisfaction with their checkups ${ }^{10,11)}$, however, they are still few in number. The study of the degree of workers' satisfaction with their checkups warrants further investigation.

In the study of the degree of patient satisfaction with their healthcare, factors related to healthcare providers (e.g., the healthcare providers' technical and interpersonal aspects of care) greatly influenced that degree ${ }^{2-4)}$. Moreover, these factors greatly influenced adherence ${ }^{5-6)}$. In our previous study on workers' satisfaction with their annual health checkups, the degree of the workers' satisfaction with their checkups was also significantly associated with factors related to healthcare providers, e.g., the consultation with a physician and the skills of the persons conducting those examinations ${ }^{10}$. The core service of the healthcare industry is to protect human life and health. Therefore, healthcare providers are required to exhibit a high level of expertise as patients and examinees highly value their efforts.

Moreover, it is also essential that healthcare providers protect examinees' privacy and have good manners. The lack of these would hinder the proper delivery of any healthcare service. If examinees were worried about privacy invasion issues, they may hold back from conveying or asking about their health conditions during the checkups. If the physician or the persons conducting the examinations have bad manners, the examinees may hesitate to describe their health conditions accurately to them or ask questions about their health conditions and healthcare.

In the present study, the predictors in the process involved in receiving annual health checkups is classified into three concepts: 1 . the core service of annual health checkups, 2. the hindrance of the core service of annual health checkups, and 3. the environment for annual health checkups. It is critical to develop a good environment for annual health checkups. However, this study hypothesizes that the degree of examinees' satisfaction with their health checkups is significantly associated with the factors related to the core service and the hindrance of that service.

The workers' attitudes toward their annual health checkups also influence the degree of their satisfaction with those checkups. Moreover, their perceptions of their health and diseases may also affect their satisfaction toward receiving annual health checkups. We hypothesized that these attitudes and perceptions are predictors significantly associated with workers' satisfaction with their annual health checkups. Healthcare organizations providing the annual health checkups could pursue these issues through various activities, including promoting primary preventions, e.g., medical education. The objective of the present study was, therefore, to investigate the clues for improving Japanese workers' satisfaction with their annual health checkups using an anonymous self-administered questionnaire.

\section{Subjects and Methods}

The subjects for this study were 2,241 workers of 5 companies who underwent the annual health checkups of the Tokyo Health Service Association from September 25 to November 30, 2007. The staff went to each company to give the checkups. The subjects of this study were all white-collar workers, e.g., sales staff and clerks. The examinees first registered at the reception desk, and each examinee underwent an examination and received a consultation with a physician.

Before they received their consultation, they filled out a health survey questionnaire prepared by the Association regarding their health condition. The physician, subsequently, conducted the consultation while looking at the questionnaire. The physician's consultation ran an average of $3 \mathrm{~min}$ per examinee. When there are large numbers of examinees for the checkups, the Association staff asks the companies to arrange more than one physician. In the present study, one or two physicians were giving the consultations.

The healthcare providers other than physicians, e.g., nurses and clinical technologists, were in charge of the examinations. For the companies that asked their workers to undergo tests even though they are not required by law ${ }^{7)}$, e.g., fundoscopy and/or ultrasonography, the Association provided the tests. The number of persons conducting examinations differs according to the number of examinees and examinations. In the present study, 7 to 15 people conducted the examinations for each annual health checkup.

After the examinations and the consultation, the examinees received an anonymous self-administered questionnaire (original version in Japanese, see the Appendix), an envelope to return it, and a description of the study (original version in Japanese). The description included: 1. the 
study's objective and methods, 2. the fact that there is no penalty to those who opt not to participate in the study and the fact that submitting the questionnaire indicates the respondent's consent to participate, 3. a statement of privacy protection and how the data would be managed, 4. the intent that the outcome of this study would be published in academic journals and/or presented at academic conferences, 5. the names and positions of researchers, and 6. the first author's contact information. The completed questionnaire was put into the envelope, sealed, and then put into a questionnaire collection box placed at the site of the annual health checkups.

\section{Questions}

1. The degree of the examinees' satisfaction with their annual health checkups

This was determined by the question, "Today's annual health checkup was generally satisfactory". The examinees selected their responses from a 7-point scale from "Definitely disagree" to "Definitely agree" (original version in Japanese).

\section{The process of the annual health checkups}

The items related to the environment for the examination were: the receptionist's good manners, an easy-tofind location, the cleanliness of the examination site, and the long waiting time. The items related to hindering the core service of the annual health checkups were the good manners of persons conducting examinations, the physician's good manners, and privacy invasion issues. The items related to the core service of the annual health checkups were anxiety about the skills of the persons conducting the examinations and any helpful advice they received from a physician. For each item, the examinees selected their responses from a 7-point scale from "Definitely disagree" to "Definitely agree".

3. The examinees' attitudes toward annual health checkups and their perceptions of health and diseases

We originally added the following four items to the questionnaire: effectiveness of the annual health checkups, the hassle of receiving annual health checkups, worrying about ones' health condition, and fear of lifestylerelated diseases. The examinees selected their responses from a 7-point scale from "Definitely disagree" to "Definitely agree".

According to the health belief model ${ }^{12,13)}$, perceived factors of benefits, barriers, susceptibility, and severity are the major factors affecting persons' preventive health measures. We thought the idea of this model was useful to produce items regarding the examinees' attitudes toward the annual health checkups and perceptions of health and diseases. The items to determine the effec- tiveness of the annual health checkups, the hassle of receiving those checkups, worrying about ones' health, and the fear of lifestyle-related diseases were produced with reference to the concepts of perceived benefits, barriers, susceptibility, and severity, respectively.

Perceived susceptibility is a factor to encourage people to form preventive health behavior ${ }^{12,13)}$. Therefore, as a person worries more about his or her health, the degree of satisfaction with the annual health checkups would likely increase. However, examinees that do not manage their health properly may also worry about their health conditions. In spite of worrying about their own health conditions, these examinees may be reluctant to undergo annual health checkups. Thus, we hypothesized that worrying about your own health can be both a positive and negative factor associated with one's satisfaction with the annual health checkups.

\section{The subjects' basic attributes}

The items on the subjects' basic attributes were: age, gender, marital status (married or single), and work environment. Work environment includes, "Much deskwork in my daily work (yes or no)", and "Many physical activities in my daily work (yes or no)". For example, sales persons may have more physically active work and feel cumulative physical fatigue. On the other hand, workers with much deskwork feel cumulative mental fatigue. We hypothesized that these two different work environments affect the degree of satisfaction of the examinees' annual health checkups.

\section{Data analyses}

Pearson's correlation coefficient was calculated to clarify the correlation between the degree of the examinees' satisfaction with their annual health checkups and their ages. The Mann-Whitney $U$ test was performed for gender, marital status, and work environment. Pearson's correlation coefficients were also calculated to clarify the relationships regarding the degree of examinees' satisfaction with their annual health checkups, attitudes toward those checkups, and perceptions of health and diseases. Likewise, Pearson's correlation coefficients were calculated between the degree of that satisfaction and the process of the annual health checkups.

To investigate the factors associated with the degree of the examinees' satisfaction with their annual health checkups, standard partial regression coefficients were also computed using forced-entry multiple linear regression analysis. The degree of the examinees' satisfaction was a dependent variable. And the basic attributes of the subjects, the examinees' attitudes toward their checkups and perceptions of health and diseases, and the process for those checkups were independent variables. 
To calculate the standard partial regression coefficients and Pearson's correlation coefficients, as for age, the actual age was used as a continuous variable. With regard to the examinees' attitudes toward annual health checkups and perceptions of health and diseases, the process of annual health checkups, the degree of the examinees' satisfaction with their annual health checkups, 1 to 7 points were given in the order from "Definitely disagree" to "Definitely agree" for each item.

To calculate the standard partial regression coefficients, gender, marital status and work environments were used as dichotomous variables. The coding of dichotomous variables was: gender (male $=1$, female $=0$ ); marital status (married=1, single=0); "Much deskwork in my daily work (yes=1, no=0)"; and "Many physical activities in my daily work (yes=1, no=0)".

The statistical significance level was set at $p<0.05$. SPSS $11.5 \mathrm{~J}$ for Windows was used for all statistical analyses.

\section{Subjects analyzed}

The questionnaires of 1,463 respondents from among the 2,241 subjects were collected. Among the questionnaires of those 1,463 respondents, questionnaires with one or more missing values were excluded from the analyses. Consequently, 1,389 questionnaires were analyzed for the statistical analyses. The average age of the analyzed subjects was $37.4 \mathrm{yr}$ (range, 18-66 yr). The average age of men $(n=843)$ was $39.3 \mathrm{yr}$ (range, 19-66 yr). The average age of women $(\mathrm{n}=546)$ was $34.5 \mathrm{yr}$ (range, 18-64 yr) (Table 1).

\section{Results}

Relationships between the degree of the examinees' sat- isfaction with their annual health checkups and the subjects' basic attributes are shown in Table 2. The MannWhitney $U$ test shows there was a significant difference in the degree of the examinees' satisfaction with their annual health checkups with respect to gender $(p=0.001)$. Men were generally more satisfied than women with their annual health checkups.

Relationships regarding the degree of examinees' satisfaction with annual health checkups, attitudes toward those checkups, and perceptions of health and diseases are shown in Table 3. The degree of such satisfaction had significant positive correlations with the effectiveness of the annual health checkups (Pearson's correlation coefficient $[\mathrm{r}]=0.386, p<0.001)$ and fear of lifestyle-related diseases $(\mathrm{r}=0.129, p<0.001)$. The degree of such satisfaction had a significant negative correlation with the hassle of receiving annual health checkups $(\mathrm{r}=-0.212, p<0.001)$.

Relationships between the degree of examinees' satisfaction with annual health checkups and the process of the annual health checkups are shown in Table 4. The degree of such satisfaction had significant positive correlations with the receptionist's good manners ( $\mathrm{r}=0.313$, $p<0.001$ ), easy-to-find location ( $\mathrm{r}=0.271, p<0.001)$, cleanliness of the examination site $(\mathrm{r}=0.396, p<0.001)$, the good manners of the persons conducting the examinations

Table 1. Distribution of analyzed subjects

\begin{tabular}{rrrr}
\hline Age & Male & Female & Total \\
\hline-29 & $197(23.4 \%)$ & $237(43.4 \%)$ & $434(31.2 \%)$ \\
$30-39$ & $307(36.4 \%)$ & $165(30.2 \%)$ & $472(34.0 \%)$ \\
$40-49$ & $139(16.5 \%)$ & $55(10.1 \%)$ & $194(14.0 \%)$ \\
$50-$ & $200(23.7 \%)$ & $89(16.3 \%)$ & $289(20.8 \%)$ \\
\hline Total & $843(100 \%)$ & $546(100 \%)$ & $1,389(100 \%)$ \\
\hline
\end{tabular}

Table 2. Relationships between the degree of examinees' satisfaction with their annual health checkups and the subjects' basic attributes

\begin{tabular}{|c|c|c|c|c|c|c|c|c|c|}
\hline & $\begin{array}{l}\text { Definitely } \\
\text { agree }\end{array}$ & Agree & $\begin{array}{l}\text { Somewhat } \\
\text { agree }\end{array}$ & $\begin{array}{l}\text { Neither agree } \\
\text { nor disagree }\end{array}$ & $\begin{array}{l}\text { Somewhat } \\
\text { disagree }\end{array}$ & Disagree & $\begin{array}{c}\text { Definitely } \\
\text { disagree }\end{array}$ & Total & \\
\hline \multicolumn{10}{|l|}{ Age } \\
\hline-29 & $101(23.3 \%)$ & $178(41.0 \%)$ & $76(17.5 \%)$ & $51(11.8 \%)$ & $12(2.8 \%)$ & $9(2.1 \%)$ & $7(1.6 \%)$ & $434(100 \%)$ & \\
\hline $30-39$ & $72(15.3 \%)$ & $212(44.9 \%)$ & $67(14.2 \%)$ & $72(15.3 \%)$ & $22(4.7 \%)$ & $20(4.2 \%)$ & $7(1.5 \%)$ & $472(100 \%)$ & $\mathrm{r}=0.009$ \\
\hline $40-49$ & $30(15.5 \%)$ & $85(43.8 \%)$ & $40(20.6 \%)$ & $22(11.3 \%)$ & $8(4.1 \%)$ & $7(3.6 \%)$ & $2(1.0 \%)$ & $194(100 \%)$ & $p=0.727$ \\
\hline $50-$ & $44(15.2 \%)$ & $146(50.5 \%)$ & $49(17.0 \%)$ & $38(13.1 \%)$ & $8(2.8 \%)$ & $3(1.0 \%)$ & $1(0.3 \%)$ & $289(100 \%)$ & \\
\hline \multicolumn{10}{|l|}{ Gender } \\
\hline Male & $158(18.7 \%)$ & $398(47.2 \%)$ & $142(16.8 \%)$ & $87(10.3 \%)$ & $22(2.6 \%)$ & $27(3.2 \%)$ & $9(1.1 \%)$ & $843(100 \%)$ & \\
\hline Female & $89(16.3 \%)$ & $223(40.8 \%)$ & $90(16.5 \%)$ & $96(17.6 \%)$ & $28(5.1 \%)$ & $12(2.2 \%)$ & $8(1.5 \%)$ & $546(100 \%)$ & $p=0.001$ (Mann-Whitney U test) \\
\hline \multicolumn{10}{|c|}{ Marital status } \\
\hline Married & $113(15.5 \%)$ & $350(48.1 \%)$ & $125(17.2 \%)$ & $88(12.1 \%)$ & $25(3.4 \%)$ & $18(2.5 \%)$ & $9(1.2 \%)$ & $728(100 \%)$ & \\
\hline Single & $134(20.3 \%)$ & $271(41.0 \%)$ & $107(16.2 \%)$ & $95(14.4 \%)$ & $25(3.8 \%)$ & $21(3.2 \%)$ & $8(1.2 \%)$ & $661(100 \%)$ & $p=0.909$ (Mann-Whitney U test) \\
\hline \multicolumn{10}{|c|}{ "There is much deskwork in my daily work." } \\
\hline Yes & $183(17.1 \%)$ & $479(44.7 \%)$ & $181(16.9 \%)$ & $139(13.0 \%)$ & $43(4.0 \%)$ & $33(3.1 \%)$ & $14(1.3 \%)$ & $1,072(100 \%)$ & \\
\hline No & $64(20.2 \%)$ & $142(44.8 \%)$ & $51(16.1 \%)$ & $44(13.9 \%)$ & $7(2.2 \%)$ & $6(1.9 \%)$ & $3(0.9 \%)$ & $317(100 \%)$ & $p=0.127$ (Mann-Whitney $\mathrm{U}$ test $)$ \\
\hline \multicolumn{10}{|c|}{ "There are many physical activities in my daily work." } \\
\hline Yes & $64(19.8 \%)$ & $142(44.0 \%)$ & $53(16.4 \%)$ & $46(14.2 \%)$ & $6(1.9 \%)$ & $7(2.2 \%)$ & $5(1.5 \%)$ & $323(100 \%)$ & \\
\hline No & $183(17.2 \%)$ & $479(44.9 \%)$ & $179(16.8 \%)$ & $137(12.9 \%)$ & $44(4.1 \%)$ & $32(3.0 \%)$ & $12(1.1 \%)$ & $1,066(100 \%)$ & $p=0.310$ (Mann-Whitney $\mathrm{U}$ test $)$ \\
\hline Total & $247(17.8 \%)$ & $621(44.7 \%)$ & $232(16.7 \%)$ & $183(13.2 \%)$ & $50(3.6 \%)$ & $39(2.8 \%)$ & $17(1.2 \%)$ & $1,389(100 \%)$ & \\
\hline
\end{tabular}

r, Pearson's correlation coefficient 
Table 3. Relationships regarding the degree of examinees' satisfaction with their annual health checkups, attitudes toward those checkups, and perceptions of health and diseases

\begin{tabular}{|c|c|c|c|c|c|c|c|c|c|c|}
\hline & $\begin{array}{c}\text { Definitely } \\
\text { agree }\end{array}$ & Agree & $\begin{array}{l}\text { Somewhat } \\
\text { agree }\end{array}$ & $\begin{array}{l}\text { Neither agree } \\
\text { nor disagree }\end{array}$ & $\begin{array}{c}\text { Somewhat } \\
\text { disagree }\end{array}$ & Disagree & $\begin{array}{c}\text { Definitely } \\
\text { disagree }\end{array}$ & Total & $\mathrm{r}$ & $p$ value \\
\hline \multicolumn{11}{|c|}{ Effectiveness of annual health checkups } \\
\hline Definitely agree & $166(35.9 \%)$ & $211(45.7 \%)$ & $41(8.9 \%)$ & $31(6.7 \%)$ & $5(1.1 \%)$ & $5(1.1 \%)$ & $3(0.6 \%)$ & $462(100 \%)$ & & \\
\hline Agree & $64(11.2 \%)$ & $296(51.9 \%)$ & $111(19.5 \%)$ & $68(11.9 \%)$ & $17(3.0 \%)$ & $11(1.9 \%)$ & $3(0.5 \%)$ & $570(100 \%)$ & & \\
\hline Somewhat agree & $8(3.9 \%)$ & $69(33.3 \%)$ & $66(31.9 \%)$ & $47(22.7 \%)$ & $10(4.8 \%)$ & $6(2.9 \%)$ & $1(0.5 \%)$ & $207(100 \%)$ & & \\
\hline Neither agree nor disagree & $2(5.7 \%)$ & $6(17.1 \%)$ & $6(17.1 \%)$ & $13(37.1 \%)$ & $3(8.6 \%)$ & $4(11.4 \%)$ & $1(2.9 \%)$ & $35(100 \%)$ & & \\
\hline Somewhat disagree & $1(2.6 \%)$ & $11(28.9 \%)$ & $1(2.6 \%)$ & $10(26.3 \%)$ & $9(23.7 \%)$ & $4(10.5 \%)$ & $2(5.3 \%)$ & $38(100 \%)$ & & \\
\hline Disagree & $4(6.2 \%)$ & $23(35.4 \%)$ & $7(10.8 \%)$ & $12(18.5 \%)$ & $6(9.2 \%)$ & $9(13.8 \%)$ & $4(6.2 \%)$ & $65(100 \%)$ & & \\
\hline Definitely disagree & $2(16.7 \%)$ & $5(41.7 \%)$ & $0(0.0 \%)$ & $2(16.7 \%)$ & $0(0.0 \%)$ & $0(0.0 \%)$ & $3(25.0 \%)$ & $12(100 \%)$ & 0.386 & $<0.001$ \\
\hline \multicolumn{11}{|c|}{ The hassle of receiving annual health checkups } \\
\hline Definitely agree & $1(7.1 \%)$ & $3(21.4 \%)$ & $2(14.3 \%)$ & $4(28.6 \%)$ & $2(14.3 \%)$ & $1(7.1 \%)$ & $1(7.1 \%)$ & $14(100 \%)$ & & \\
\hline Agree & $2(7.4 \%)$ & $14(51.9 \%)$ & $2(7.4 \%)$ & $4(14.8 \%)$ & $2(7.4 \%)$ & $2(7.4 \%)$ & $1(3.7 \%)$ & $27(100 \%)$ & & \\
\hline Somewhat agree & $23(11.1 \%)$ & $79(38.2 \%)$ & $58(28.0 \%)$ & $33(15.9 \%)$ & $3(1.4 \%)$ & $8(3.9 \%)$ & $3(1.4 \%)$ & $207(100 \%)$ & & \\
\hline Neither agree nor disagree & $9(7.7 \%)$ & $40(34.2 \%)$ & $25(21.4 \%)$ & $32(27.4 \%)$ & $5(4.3 \%)$ & $2(1.7 \%)$ & $4(3.4 \%)$ & $117(100 \%)$ & & \\
\hline Somewhat disagree & $8(7.9 \%)$ & $40(39.6 \%)$ & $18(17.8 \%)$ & $17(16.8 \%)$ & $12(11.9 \%)$ & $3(3.0 \%)$ & $3(3.0 \%)$ & $101(100 \%)$ & & \\
\hline Disagree & $28(10.4 \%)$ & $152(56.5 \%)$ & $46(17.1 \%)$ & $28(10.4 \%)$ & $6(2.2 \%)$ & $7(2.6 \%)$ & $2(0.7 \%)$ & $269(100 \%)$ & & \\
\hline Definitely disagree & $176(26.9 \%)$ & $293(44.8 \%)$ & $81(12.4 \%)$ & $65(9.9 \%)$ & $20(3.1 \%)$ & $16(2.4 \%)$ & $3(0.5 \%)$ & $654(100 \%)$ & -0.212 & $<0.001$ \\
\hline \multicolumn{11}{|c|}{ Worry about one's health condition } \\
\hline Definitely agree & $26(33.8 \%)$ & $26(33.8 \%)$ & $9(11.7 \%)$ & $9(11.7 \%)$ & $3(3.9 \%)$ & $3(3.9 \%)$ & $1(1.3 \%)$ & $77(100 \%)$ & & \\
\hline Agree & $31(15.1 \%)$ & $106(51.7 \%)$ & $29(14.1 \%)$ & $22(10.7 \%)$ & $9(4.4 \%)$ & $6(2.9 \%)$ & $2(1.0 \%)$ & $205(100 \%)$ & & \\
\hline Somewhat agree & $58(15.1 \%)$ & $168(43.6 \%)$ & $86(22.3 \%)$ & $52(13.5 \%)$ & $11(2.9 \%)$ & $7(1.8 \%)$ & $3(0.8 \%)$ & $385(100 \%)$ & & \\
\hline Neither agree nor disagree & $79(16.3 \%)$ & $209(43.2 \%)$ & $83(17.1 \%)$ & $76(15.7 \%)$ & $15(3.1 \%)$ & $16(3.3 \%)$ & $6(1.2 \%)$ & $484(100 \%)$ & & \\
\hline Somewhat disagree & $6(12.8 \%)$ & $13(27.7 \%)$ & $12(25.5 \%)$ & $9(19.1 \%)$ & $5(10.6 \%)$ & $1(2.1 \%)$ & $1(2.1 \%)$ & $47(100 \%)$ & & \\
\hline Disagree & $16(14.0 \%)$ & $67(58.8 \%)$ & $11(9.6 \%)$ & $8(7.0 \%)$ & $5(4.4 \%)$ & $5(4.4 \%)$ & $2(1.8 \%)$ & $114(100 \%)$ & & \\
\hline Definitely disagree & $31(40.3 \%)$ & $32(41.6 \%)$ & $2(2.6 \%)$ & $7(9.1 \%)$ & $2(2.6 \%)$ & $1(1.3 \%)$ & $2(2.6 \%)$ & $77(100 \%)$ & -0.016 & 0.544 \\
\hline \multicolumn{11}{|l|}{ Fear of lifestyle-related diseases } \\
\hline Definitely agree & $120(27.4 \%)$ & $195(44.5 \%)$ & $49(11.2 \%)$ & $49(11.2 \%)$ & $14(3.2 \%)$ & $8(1.8 \%)$ & $3(0.7 \%)$ & $438(100 \%)$ & & \\
\hline Agree & $73(15.4 \%)$ & $237(49.9 \%)$ & $66(13.9 \%)$ & $61(12.8 \%)$ & $15(3.2 \%)$ & $17(3.6 \%)$ & $6(1.3 \%)$ & $475(100 \%)$ & & \\
\hline Somewhat agree & $27(9.7 \%)$ & $118(42.4 \%)$ & $74(26.6 \%)$ & $38(13.7 \%)$ & $11(4.0 \%)$ & $6(2.2 \%)$ & $4(1.4 \%)$ & $278(100 \%)$ & & \\
\hline Neither agree nor disagree & $11(10.2 \%)$ & $38(35.2 \%)$ & $21(19.4 \%)$ & $27(25.0 \%)$ & $5(4.6 \%)$ & $3(2.8 \%)$ & $3(2.8 \%)$ & $108(100 \%)$ & & \\
\hline Somewhat disagree & $4(13.8 \%)$ & $8(27.6 \%)$ & $7(24.1 \%)$ & $5(17.2 \%)$ & $2(6.9 \%)$ & $3(10.3 \%)$ & $0(0.0 \%)$ & $29(100 \%)$ & & \\
\hline Disagree & $5(11.4 \%)$ & $22(50.0 \%)$ & $12(27.3 \%)$ & $3(6.8 \%)$ & $0(0.0 \%)$ & $1(2.3 \%)$ & $1(2.3 \%)$ & $44(100 \%)$ & & \\
\hline Definitely disagree & $7(41.2 \%)$ & $3(17.6 \%)$ & $3(17.6 \%)$ & $0(0.0 \%)$ & $3(17.6 \%)$ & $1(5.9 \%)$ & $0(0.0 \%)$ & $17(100 \%)$ & 0.129 & $<0.001$ \\
\hline Total & $247(17.8 \%)$ & $621(44.7 \%)$ & $232(16.7 \%)$ & $183(13.2 \%)$ & $50(3.6 \%)$ & $39(2.8 \%)$ & $17(1.2 \%)$ & $1,389(100 \%)$ & & \\
\hline
\end{tabular}

r, Pearson's correlation coefficient

$(\mathrm{r}=0.387, \quad p<0.001)$, the physician's good manners $(\mathrm{r}=0.401, p<0.001)$, and helpful advice from a physician $(\mathrm{r}=0.373, p<0.001)$. The degree of their satisfaction had significant negative correlations with the long waiting time $(\mathrm{r}=-0.129, \quad p<0.001)$, privacy invasion issues $(\mathrm{r}=-0.287, p<0.001)$, and the anxiety about the skills of the persons conducting the examinations $(\mathrm{r}=-0.350$, $p<0.001)$.

Factors associated with the degree of examinees' satisfaction with their annual health checkups are shown in Table 5. The degree of such satisfaction was associated with the effectiveness of their annual health checkups (standard partial regression coefficient $[\beta]=0.256$, $p<0.001)$, the hassle of receiving annual health checkups $(\beta=-0.071, p=0.001)$, the receptionist's good manners ( $\beta=0.059, p=0.026)$, cleanliness of the examination site $(\beta=0.142, p<0.001)$, the long waiting time $(\beta=-0.053$, $p=0.016)$, privacy invasion issues $(\beta=-0.071, p=0.004)$, anxiety about the skills of the persons conducting exam- inations $(\beta=-0.121, p<0.001)$, and helpful advice from a physician $(\beta=0.240, p<0.001)$. The adjusted $\mathrm{R}^{2}$ value of the multiple regression analysis was 0.387 .

\section{Discussion}

In this paper, we examined the factors associated with examinees' satisfaction with their annual health checkups. These factors are classified into 3 categories as follows: 1. the subjects' basic attributes, 2. the examinees' attitudes toward the annual health checkups and their perceptions of health and diseases, and 3. the process of the annual health checkups. As previously mentioned, the items concerning the processes of receiving annual health checkups were classified as three concepts related to: the core service of annual health checkups, the hindrance to the core service of annual health checkups, and the environment for the annual health checkups.

There were three limitations to the present study. The 
Table 4. Relationships between the degree of examinees' satisfaction with their annual health checkups and the process of those checkups

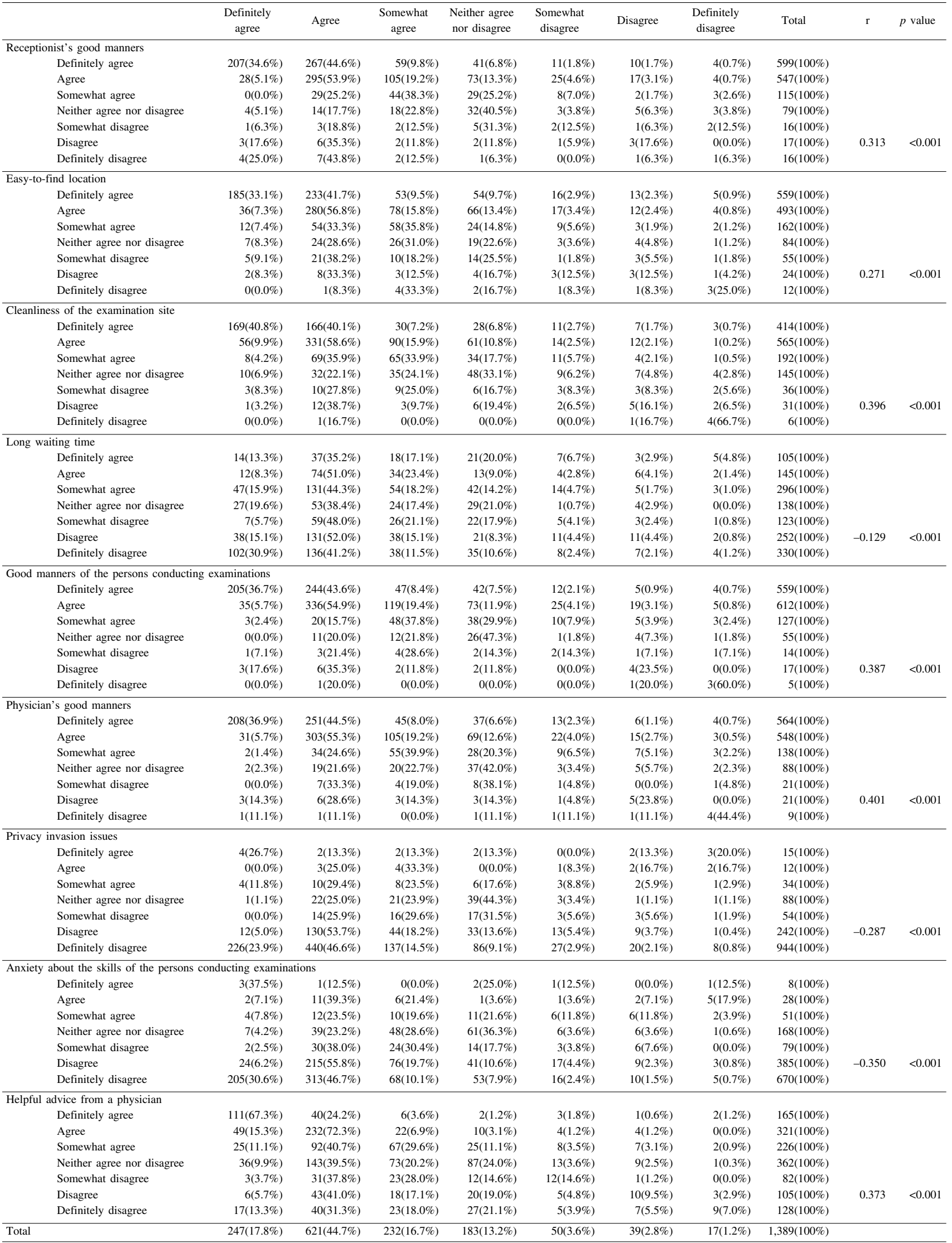

r, Pearson's correlation coefficient 
Table 5. Factors associated with the degree of the examinees' satisfaction with their annual health checkups

\begin{tabular}{lrrr}
\hline & $\beta$ & $p$ value & VIF \\
\hline Age & -0.017 & 0.535 & 1.706 \\
Gender & 0.043 & 0.063 & 1.214 \\
Marital status & 0.006 & 0.829 & 1.644 \\
Much deskwork in my daily work & -0.005 & 0.871 & 1.861 \\
Many physical activities in my daily work & 0.011 & 0.684 & 1.795 \\
Effectiveness of annual health checkups & 0.256 & $<0.001$ & 1.118 \\
The hassle of receiving annual health checkups & -0.071 & 0.001 & 1.107 \\
Worry about one's health condition & -0.005 & 0.832 & 1.075 \\
Fear of lifestyle-related diseases & 0.013 & 0.536 & 1.078 \\
Receptionist's good manners & 0.059 & 0.026 & 1.575 \\
Easy-to-find location & -0.002 & 0.942 & 1.503 \\
Cleanliness of the examination site & 0.142 & $<0.001$ & 1.550 \\
Long waiting time & -0.053 & 0.016 & 1.102 \\
Good manners of the persons conducting examinations & 0.048 & 0.166 & 2.721 \\
Physician's good manners & 0.058 & 0.084 & 2.553 \\
Privacy invasion issues & -0.071 & 0.004 & 1.352 \\
Anxiety about the skills of the persons conducting examinations & -0.121 & $<0.001$ & 1.346 \\
Helpful advice from a physician & 0.240 & $<0.001$ & 1.194 \\
\hline
\end{tabular}

Adjusted $\mathrm{R}^{2}=0.387$

$\beta$, standard partial regression coefficient; VIF, variance inflation factor

first limitation was that we used a cross-sectional design, which made it difficult to evidence any identifying factors referring to causal relationships. The second limitation was that 1,463 of 2,241 questionnaires were collected. Because the questionnaires with one or more missing values were excluded for the analyses, a total of 1,389 questionnaires were analyzed. Thus, the opinions of 852 subjects were not included in this study. The third limitation was that the sampling method was not random sampling. Therefore, the generalizability of our results is not confirmed.

The degree of the examinees' satisfaction with their annual health checkups was significantly associated with the effectiveness of the annual health checkups and the hassle of receiving those checkups. The effectiveness of annual health checkups is a factor included in the concept of perceived benefits in the health belief model ${ }^{12,13)}$. And the hassle of receiving annual health checkups is a factor included in the concept of barriers ${ }^{12,13)}$.

In our previous study ${ }^{14)}$, we examined the factors in improving workers' use of the results of their annual health checkups. The workers who, after attending health consultations with occupational health staff, recognized that health lifestyle habits are effective to prevent lifestyle-related diseases used their results of their checkups to their own healthful benefit ${ }^{14)}$. If examinees cannot recognize the effectiveness of annual health checkups, they cannot recognize the reasons for getting the health checkups annually, thus decreasing their degree of satis- faction with them. Moreover, if examinees were not interested in their health, they naturally would not be interested in getting health checkups annually. As a result, they would probably feel that it was a hassle to receive those checkups.

Medical education is necessary to convey the effectiveness of annual health checkups to examinees and to reduce the hassle of receiving those checkups. For instance, the attempt to provide understandable instructions on how to read the results of the annual health checkups could be a useful means of deepening the examinees' general medical knowledge ${ }^{15)}$. As another useful means, the healthcare organizations providing the checkups could hold seminars regarding those checkups at convenient times and locations at the examinees' companies. The organizations providing the checkups must endeavor not only to promote early detection of diseases but also to conduct various activities, including promoting primary preventions.

The degree of the examinees' satisfaction with their annual health checkups was significantly associated with the helpful advice from a physician, the anxiety about the skills of the persons conducting the examinations, and privacy invasion issues. The first two items (i.e., the helpful advice given by a physician and the anxiety about the skills of the persons conducting the examinations) applied to the conception of the core service of annual health checkups. The privacy invasion issue applies to the conception of the hindrance to the core service of annual 
health checkups.

In the studies of patient satisfaction ${ }^{2-6)}$ and our previous report ${ }^{10)}$, factors related to healthcare providers greatly influence the degree of their satisfaction or adherence. It is necessary to recognize that healthcare providers who conduct annual health checkups particularly affect the degree of the examinees' satisfaction.

According to surveys on patient satisfaction ${ }^{5-6)}$, when their satisfaction concerning healthcare providers is high, their adherence increases. If a physician conducts appropriate consultations, there is a high possibility that the examinees' motivation toward health management improves, e.g., they make efforts to "put their physician's advice into practice in their daily lives to manage their own healthcare".

When annual health checkups are given, it is necessary for the healthcare providers to complete the examinations and consultations within a limited amount of time. In some cases, sufficient time cannot be allocated for consultations with a physician. Accordingly, it is necessary to devise better ways of providing these consultations. For instance, it would be useful to prepare a brief manual regarding these consultations to facilitate the physicians to give the examinees more helpful advice.

Privacy invasion issues discourage workers from receiving health consultations with an occupational physician at a manufacturing plant ${ }^{16)}$. This could also be true with the staff providing the annual health checkups. If examinees are worried about privacy invasion issues, they may hold back from explaining their true health conditions to the staff. It is, therefore, necessary to intensify matters related to privacy protection.

We hypothesized that the degree of examinees' satisfaction with annual health checkups was not significantly associated with the environment for those checkups. However, this study revealed that three factors (i.e., the receptionist's good manners, the long waiting time, and cleanliness of the examination site) significantly affected the degree of the examinees' satisfaction.

An examinee first goes to the receptionist, then receives an examination and a consultation with a physician. Thus, among the annual health checkup staff, the receptionist is the first person with whom an examinee comes into contact. If the receptionist's manners are not good, it will make a bad first impression upon the examinee. It is imperative, therefore, for the receptionists to have good manners.

Moreover, the lack of cleanliness is not comfortable to anyone. Because the number of examinees who emphasized cleanliness was significantly large, the staffs providing the checkups need to especially pay careful attention to the cleanliness of the examination sites.

Ezaki et al. also reported that the degree of the exam- inees' satisfaction with their annual health checkups was significantly associated with the long waiting time ${ }^{11}$. Workers undergo annual health checkups during their regular working hours. It seems to be difficult for workers to make time for health checkups because they are so busy. Therefore, ways to cut down the waiting time must be devised, e.g., getting workers to make appointments for their checkups.

\section{Conclusions}

The factors significantly associated with workers' satisfaction with annual health checkups were helpful advice from a physician, anxiety concerning the skills of the persons conducting the examinations, and privacy invasion issues. These three factors included the core service and hindrance to that service in the process of the annual health checkups. The providers of the checkups must discuss these factors among themselves in order to improve the quality of the checkups. Moreover, regarding the environment for those checkups, the factors significantly associated with workers' satisfaction with the checkups were the receptionist's good manners, the cleanliness of the examination site, and the long waiting time.

Furthermore, the perception of the effectiveness of the checkups and the hassle of receiving them was significantly associated with the degree of workers' satisfaction. Regarding the responsibility of the organizations providing the checkups, the early detection of diseases alone is not sufficient. Through primary prevention, e.g., medical education, it is necessary to convince the examinees of the effectiveness of the annual health checkups and to convince them that it is not a hassle to receive them annually.

\section{References}

1) Donabedian A (1980) The definition of quality: a conceptual exploration. In: Explorations in quality assessment and monitoring, Vol. 1, The definition of quality and approaches to its assessment. Health Administration Press, Ann Arbor, Michigan.

2) Cleary PD, McNeil BJ (1988) Patient satisfaction as an indicator of quality care. Inquiry 25, 25-36.

3) Imanaka Y, Araki S, Murata K, Nobutomo K (1993) Determinants of patient satisfaction and intention to continue service utilization. Analysis of a survey of outpatients at a general hospital. Nihon Koshu Eisei Zasshi 40, 624-35 (in Japanese with English Abstract).

4) Hasegawa M, Sugita S (1993) Factors determining patient satisfaction with their medical care. Byouinkanri 30, 231-9 (in Japanese with English abstract).

5) Rosenberg MJ, Waugh MS, Burnhill MS (1998) Compliance, counseling and satisfaction with oral con- 
traceptives: a prospective evaluation. Fam Plann Perspect 30, 89-92, 104.

6) Roberts KJ (2002) Physician-patient relationships, patient satisfaction, and antiretroviral medication adherence among HIV-infected adults attending a public health clinic. AIDS Patient Care STDS 16, 43-50.

7) Ministry of Health, Labour and Welfare (2000) Handbook of general health checkup, Japan Industrial Safety and Health Association, Tokyo (in Japanese).

8) Irie M, Miyata M, Nagata S, Mishima N, Ikeda M, Hirayama S (1997) Psychosocial evaluation on the correct recollection of periodic medical checkups of workers. 1. The ratio of correctly recalled results of medical checkups. San Ei Shi 39, 193-202 (in Japanese with English abstract).

9) Irie $M$, Nagata S, Miyata M, Ikeda M, Hirayama S (1998) Psychosocial evaluation on the correct recollection of periodic medical checkups of workers. 2. Longterm change in the recalled results of medical checkups. San Ei Shi 40, 75-84 (in Japanese with English abstract).

10) Kudo Y, Satoh T, Hosoi K, Aizawa Y (2004) Factors associated with satisfaction among participants in a periodical worksite health check-up in Japan. J Occup Health 46, 461-9.

11) Ezaki T, Honda S, Hashimoto H, Jahng D (1999) Employees' satisfaction and the influential process factors during regular health check-up by a contracted industrial health association. San Ei Shi 41, 159-65 (in Japanese with English abstract).

12) Rosenstock IM (1974) Historical origins of the health belief model. In: The health belief model and preventive health behavior, Becker MH (Ed.), 1-8, Charles B. Slack, New Jersey.

13) Rosenstock IM (1974) Health belief model and preventive health behavior. In: The health belief model and preventive health behavior, Becker MH (Ed.), 27-59, Charles B. Slack, New Jersey.

14) Kudo $Y$, Satoh T, Kido S, Ishibashi M, Miyajima E, Watanabe M, Miki T, Tsunoda M, Aizawa Y (2008) The degree of workers' use of annual health checkup results among Japanese workers. Ind Health 46, 223-32.

15) Kudo Y, Satoh T, Okada M, Shinohara S, Morita I, Miyajima E, Watanabe M, Miki T, Miwa Y, Aizawa Y (2007) Survey of the degree of examinees'satisfaction with instructions on how to read results of general health checkups at a workplace. Ind Health 45, 503-11.

16) Kudo $Y$, Satoh $T$, Ishibashi M, Miyajima E, Watanabe M, Miki T, Kido S, Aizawa Y (2007) Factors associated with workers' perceived helpfulness of and need for health consultations given by an occupational physician at a Japanese manufacturing plant. J Occup Environ Med 49, 1157-64.

\section{Appendix: Questionnaire Items (Original ver- sion in Japanese)}

\section{The process for the annual health checkups}

The environment for the annual health checkups

1. The receptionist's manners in today's annual health checkup were good.

2. The location of the reception desk, examinations, and consultation was easy to find in today's annual health checkup.

3. The site for today's annual health checkup was sanitary.

4. The waiting time for today's annual health checkup was long.

Hindrance to the core service of the annual health checkups

5. The persons conducting the examinations in today's annual health checkup had good manners.

6. The physician conducting the consultation in today's annual health checkup had good manners.

7. I felt my privacy was invaded during today's annual health checkup.

The core service of the annual health checkups

8. During today's annual health checkup, I was anxious about the skills of the persons conducting the examinations.

9. During today's annual health checkup, I received helpful advice concerning my health management from the physician conducting the consultation.

\section{The examinees' attitudes toward the annual health} checkups and their perceptions of health and diseases

1. I think annual health checkups are an effective way of maintaining my health.

2. I feel receiving annual health checkups is a hassle.

3. I worry that my health condition will become worse in the near future.

4. I know the diseases that occur due to poor lifestyle habits are serious.

\section{Subjects' basic attributes}

1. Age: ( years old $)$

2. Gender: $\square$ Male $\square$ Female

3. Marital status: $\square$ Married $\square$ Single

4. There is much deskwork in my daily work.

$\square$ Yes $\quad \square$ No

5. There are many physical activities in my daily work. $\square$ Yes $\quad \square$ No 